\title{
Study on Renal Function in Acute Diarrheal Disease with Dehydration
}

\author{
S Surya Veera Kumar', G Kalyan Chakravarthi ${ }^{2}$ \\ ${ }^{1}$ Assistant Professor, Department of Paediatrics, GSL Medical College \& General Hospital, Rajahmundry (A.P.), ${ }^{2}$ Associate Professor, Department of Paediatrics, GSL \\ Medical College \& General Hospital, Rajahmundry (A.P.)
}

\section{Abstract}

Background: Decreasing trend of exclusive breast feeding and faulty practices of bottle-feeding play an important role in the causes of acute diarrhoea. The main cause of death in acute diarrhoea is dehydration, which results from the loss of fluid and electrolytes in diarrheal stools. The present work was planned to assess renal function (Blood Urea and Serum Creatinine) in acute diarrheal disease with dehydration. Subjects and Methods: The present hospital based prospective study was conducted at department of paediatrics GSL Medical College \& General Hospital, Rajahmundry, which includes consecutive patients attending OPD and inpatients in view of acute diarrhea between 1 month and 5years of age. A detailed history from the patients with acute gastroenteritis was taken .The procedure of the study was explained \&required consent for the study was taken. Examination of the patient was done \& all relevant data was obtained. Results: B. Urea levels were elevated $(>35 \mathrm{mg} / \mathrm{dl})$ in $35.1 \%$ cases and normal in $64.9 \%$ cases with mean being $44.93 \mathrm{mg} / \mathrm{dl}$. S.Creatinine levels were elevated(>0.7mg/dl) in $32 \%$ cases and rest having normal levels with mean being $0.68 \mathrm{mg} / \mathrm{dl}$. Maximum age incidence was found in age group of less than 1 yr $(50.5 \%)$. Conclusion: The present study aimed at noting the biochemical changes in patients having acute diarrhoea. Like any other electrolyte abnormalities which occur in conditions other than diarhoea, are basically asymptomatic \& does not require aggressive correction of electrolytes.

Keywords: Acute diarrheal disease, Dehydration, Blood urea, Serum creatinine.

Corresponding Author: Dr. G Kalyan Chakravarthi, Associate Professor, Department of Paediatrics, GSL Medical College \& General Hospital, Rajahmundry (A.P.)

Received: September 2019

Accepted: September 2019

\section{Introduction}

Diarrhoeal disorders in childhood account for a large proportion (9\%) of childhood deaths, with an estimated 0.71 million deaths per year globally, making it the second most common cause of child deaths worldwide. ${ }^{[1]}$

In India, acute diarrhoeal disease accounts for about $8 \%$ of deaths in under-5 years age group. During the year 2014, about 11.6 million cases with 1,323 deaths were reported in India. $^{[2]}$

The high incidence of diarrhoeal diseases in developing countries is related to under-nutrition, increased vulnerability to infections, poor education, socio-economic status and the unfortunate trend of early breast milk substitutes. Decreasing trend of exclusive breast feeding and faulty practices of bottle-feeding play an important role. The main cause of death in acute diarrhoea is dehydration, which results from the loss of fluid and electrolytes in diarrheal stools.

A study conducted in 2010 in Dhaka Shishu hospital showed that electrolyte disturbances in Acute Gastroenteritis was associated with increased morbidity, with hyponatremic dehydration in $15 \%$ cases. $^{[3]}$

Electrolyte abnormalities are common in children with diarrhoea. It may remain unrecognized and result in mortality and morbidity. Timely recognition, a high index of suspicion and thorough understanding of common electrolyte abnormalities is necessary to ensure their correction. The present study was undertaken to assess renal function in acute diarrheal disease with dehydration.

\section{Objectives:}

To assess renal function (Blood Urea and Serum Creatinine) in acute diarrheal disease with dehydration.

\section{Subjects and Methods}

The present Hospital based prospective study was conducted in Department of Paediatrics, GSL Medical College \& General Hospital, Rajahmundry. Consecutive Patients attending OPD and inpatients in view of acute diarrhea between 1 month and 5years of age.

\section{$\underline{\text { Selection criteria: }}$}

Inclusion criteria:

Children between 1 month and 5years of age (with acute gastroenteritis), Large frequent stools (3 or $>$ ), Excessive vomiting ( 4 or $>$ ), Some \& severe dehydration. 


\section{Exclusion criteria:}

Parenteral diarrhea, Gastroenteritis more than 14 days, Severe Acute Malnutrition.

\section{Method of data collection:}

A detailed history from the patients with acute gastroenteritis was taken .The procedure of the study was explained \&required consent for the study was taken. Examination of the patient was done \& all relevant data was obtained. Detailed clinical examination will be done to look for thirsty, irritability, pinched look, sunken eyes, dry inner side of cheeks, abdominal distention, deep and rapid breathing, weak and thready pulse, falling blood pressure, reduced quantity of urine according to WHO dehydration assessment scale.

\section{Laboratory investigations:}

1. Basal Hematological and Biochemical investigations were done in all patients, including hemoglobin, total and differential white cell counts, platelets \& peripheral smear examination

2. Basal blood urea nitrogen and basal random blood sugar was done in all patients.

3. Serum electrolytes were determined at ' 0 'hour(admission) and once between 24 to 48 hours(post hydration)

Hydration status was assessed by using the following signs:

Assessment of dehydration with treatment

\begin{tabular}{|c|c|c|c|}
\hline \multicolumn{4}{|l|}{ Look: } \\
\hline 1.Thirst & $\begin{array}{l}\text { Drinks } \\
\text { normally }\end{array}$ & Drinks eagerly & Unable to drink \\
\hline 2.Condition & Well, Alert & $\begin{array}{l}\text { Restless, } \\
\text { Irritable }\end{array}$ & Lethargic,unconcsious \\
\hline 3.Eyes & Normal & Sunken & Very sunken \\
\hline 4.Tears & Present & Absent & Absent \\
\hline 5.Oral cavity & Moist & Dry & Very dry \\
\hline \multicolumn{4}{|l|}{ Feel: } \\
\hline \multirow[t]{2}{*}{ Skin pinch } & Goes back & Goes back & Goes back very \\
\hline & $\begin{array}{l}\text { quickly }(<2 \\
\text { sec })\end{array}$ & slowly $(2-3 \mathrm{sec})$ & slowly $(>3 \mathrm{sec})$ \\
\hline Hydration & NO & SOME & SEVERE \\
\hline Treatment & Plan A & Plan B & Plan C \\
\hline
\end{tabular}

\section{Fluid therapy:}

This was designed to correct dehydration, electrolyte imbalance, acidosis and maintain urinary output.

\section{Statistical analysis:}

Descriptive statistics such as mean, SD and percentage was used.

\section{Results}

\section{Table 1: Age distribution}

\begin{tabular}{|l|l|l|}
\hline Age(Yrs) & Frequency & Percentage \\
\hline$<1$ & 49 & 50.5 \\
\hline $1-2$. & 17 & 17.5 \\
\hline $3-5$. & 31 & 32 \\
\hline Total & 97 & 100 \\
\hline
\end{tabular}

Majority of the patients belongs to age less than one year $(50.5 \%)$ followed by $3-5$ years $(32 \%)$ and $1-2$ years $(17.5 \%)$.

Table 2: Sex distribution

\begin{tabular}{|l|l|l|}
\hline Sex & Frequency & Percentage \\
\hline $\mathrm{M}$ & 53 & 54.6 \\
\hline $\mathrm{F}$ & 44 & 45.4 \\
\hline Total & 97 & 100 \\
\hline
\end{tabular}

In the present study, male patients $(54.6 \%)$ are more predominant than female $(45.4 \%)$

Table 3: Distribution of dehydration

\begin{tabular}{|l|l|l|}
\hline Dehydration & Frequency & Percentage \\
\hline Some & 59 & 61 \\
\hline Severe & 38 & 39 \\
\hline
\end{tabular}

In the present, severe dehydration was observed in $38(39 \%)$ patients only.

Table 4: Blood urea levels

\begin{tabular}{|l|l|l|}
\hline Blood Urea(Mg/DI) & Frequency & Percentage \\
\hline$>35$ & 34 & 35.1 \\
\hline$<35$ & 63 & 64.9 \\
\hline Total & 97 & 100 \\
\hline
\end{tabular}

Table 5: blood urea levels in different age groups of children studied (n=97).

\begin{tabular}{|l|l|l|l|}
\hline \multirow{2}{*}{ AGE(YRS) } & \multirow{2}{*}{ SEX } & \multicolumn{2}{|l|}{ BLOOD UREA (mg/dl) } \\
\cline { 3 - 4 } & & $>\mathbf{3 5}$ & $<35$ \\
\hline$<1$ & $\mathrm{M}$ & $10(10.3)$ & $17(17.5)$ \\
\cline { 2 - 4 } & $\mathrm{F}$ & $8(8.3)$ & $14(14.4)$ \\
\hline \multirow{2}{*}{$1-2}$. & $\mathrm{M}$ & $5(5.3)$ & $4(4.2)$ \\
\cline { 2 - 4 } & $\mathrm{F}$ & $2(2.1)$ & $6(6.2)$ \\
\hline \multirow{2}{*}{$3-5}$. & $\mathrm{M}$ & $6(6.2)$ & $11(11.3)$ \\
\cline { 2 - 4 } & $\mathrm{F}$ & $3(3.1)$ & $11(11.3)$ \\
\hline & TOTAL & $34(35.1)$ & $63(64.9)$ \\
\hline
\end{tabular}

Table 6: Serum Creatinine Levels In Children Studied (N=97).

\begin{tabular}{|l|l|l|}
\hline Serum Creatinine $(\mathbf{m g} / \mathbf{d l})$ & Frequency & Percentage \\
\hline$>0.7$ & 31 & 32 \\
\hline$<0.7$ & 66 & 68 \\
\hline Total & 97 & 100 \\
\hline
\end{tabular}

Table 7: Serum Creatinine Levels In Different Age Groups Studied Children Studied (N=97).

\begin{tabular}{|l|l|l|l|}
\hline \multirow{2}{*}{ Age(yrs) } & \multirow{2}{*}{ Sex } & \multicolumn{2}{|l|}{ Serum creatinine (mg/dl) } \\
\cline { 2 - 4 } & & $>\mathbf{0 . 7}$ & $<\mathbf{0 . 7}$ \\
\hline$<1$ & $\mathrm{M}$ & $9(9.3 \%)$ & $18(18.6 \%)$ \\
\cline { 2 - 4 } & $\mathrm{F}$ & $5(5.2 \%)$ & $17(17.5 \%)$ \\
\hline \multirow{2}{*}{$1-2}$. & $\mathrm{M}$ & $5(5.2 \%)$ & $4(4.1 \%)$ \\
\cline { 2 - 4 } & $\mathrm{F}$ & $2(2.1 \%)$ & $6(6.2 \%)$ \\
\hline \multirow{2}{*}{$3-5}$. & $\mathrm{M}$ & $6(6.2 \%)$ & $11(11.3 \%)$ \\
\cline { 2 - 4 } & $\mathrm{F}$ & $4(4.2 \%)$ & $10(10.3 \%)$ \\
\hline
\end{tabular}

\section{Discussion}

Age:

The most common age group in the present study was age 
less than 1 year $(50.51 \%)$ followed by $3-5$ years $(31.95 \%)$. M M Okposio et.al4 study shows similar age distribution with present study and reported, children who are less than 5 years of age of which $103(55.7 \%)$ falls under an age of $<1$ year and $82(44.3 \%)$ above 1 year.

Conway et.al, ${ }^{[5]}$ study conducted on 1148 children younger than 16 years admitted to a sub-regional infectious disease hospital with a diagnosis of gastroenteritis over a 1 year period. Of the admitted children, 55\% (635/1148) were younger than 1 year while $5 \%$ were over 5 years of age.

Habibullah babar et. al, ${ }^{[6]}$ conducted similar study, in which majority of patients admitted were below 24 months of age i.e., 114(65.5\%).

Ahmad M S et.al. ${ }^{[7]}$ According to age, 11 (10.6\%) patients were below one month, $48(46.1 \%)$ were between 1 month and 11 months, $32(30.8 \%)$ were between 1 year and 4 years and 11 months, and $13(12.5 \%)$ were 5 years.

Srivastava et.al, ${ }^{[8]}$ conducted a study, 110 hospitalized children up to 3 years of age suffering from diarrhoea were investigated. The peak of admission due to diarrhoea was in the month of June. Cases aged 0-12 months constituted $72.8 \%$ of the total number of cases.

\section{Sex:}

In this study, total 97 children where studied, male children $53(54.6 \%)$ outnumber female children $44(45.4 \%)$, with a male to female ratio of 1.2:1.

Habibullah barbar et. al, ${ }^{[6]}$ conducted similar study, in which majority of patients admitted were males $112(64.4 \%)$ and Female patients were 62(35.6).

Acute Diarrheal Disease was more common in boys than girls with the ratio of $1.2: 1$, a finding which is similar to that reported by Srivastava et al8 and Behera et al, ${ }^{[9]}$

Rebecca Oketcho et al, ${ }^{[4]}$ showed that nearly all children $(99.5 \%)$ resided in Morogoro and there were more male children $(57.9 \%)$ than female children $(42.1 \%)$.

M M Okposio et.al, ${ }^{[4]}$ study shows similar findings in age distribution. A total of 185 children met the inclusion criteria out of the 302 admitted for diarrhoeal disease during the study period. Of these, 107 (57.8\%)were males and 78 $(42.2 \%)$ were females with a male female ratio of 1.4:1.

\section{Blood Urea levels:}

In this study most of the patients $64.9 \%$ had normal urea levels followed by increased levels in $35.1 \%$ patients.

In the present study, out of 38 severely dehydrated children $20(52.6 \%)$ children had high blood urea levels and 18 $(47.3 \%)$ children had normal blood urea levels.

In present study, out of 59 some dehydrated children 45 $(76.3 \%)$ children had normal blood urea levels and 14 (23.7\%) had high blood urea levels.

Ahmad M S et.al, ${ }^{[7]}$ study, out of 104 severe dehydration patients studied Urea level was high in 88 (84.6\%) patients. Gauchan E et.al, ${ }^{[10]}$ study showed similarity with present study, high blood urea was found in 20 (90.9\%) of Severe dehydration as compared to $63(51.2 \%)$ of Some and 15 (34\%) of No dehydration.

A clinical and biochemical study by K. R. Purohit et al of 100 cases of acute diarrhoea in infancy was done, Blood urea was raised in 53 cases. ${ }^{[11]}$

\section{Serum Creatinine levels:}

In present study, majority of the patients $(68 \%)$ had normal levels followed by increased levels in $32 \%$ patients.

In the present study, out of 38 severely dehydrated children $17(44.7 \% \%)$ children had high serum creatinine levels and $21(55.3 \%)$ children had normal high serum creatinine levels.

In present study, out of 59 some dehydrated children 45 $(76.3 \%)$ children had normal serum creatinine levels and 14 $(23.7 \%)$ had. high serum creatinine levels.

Ahmad M S et.al study shows similarity with present study Creatinine level was high in $36(34.6 \%)$ patients. ${ }^{[7]}$

Alireza Soleimani et. al study showed, Out of 121 patients, 28 patients $(23.9 \%)$ serum $\mathrm{Cr}$ level was higher than 1.5 $\mathrm{mg} / \mathrm{dL}$ on admission. Of these patients, 13 persons (46.4\%) were affected by the mild form of the increase in the serum $\mathrm{Cr}(1.5<$ plasma $\mathrm{Cr}<3 \mathrm{mg} / \mathrm{dL})$ and 15 patients $(53.6 \%)$ had a plasma $\mathrm{Cr}$ level above $3 \mathrm{mg} / \mathrm{dL} .{ }^{[12]}$

Gauchan E et.al, study showed, out of 114 children studied, high serum creatinine was found in $18(81.8 \%)$ of Severe, 79 $(64 \%)$ of Some and $17(39.5 \%)$ of No dehydration. ${ }^{[10]}$

A clinical and biochemical study by K. R. Purohit et al of 100 cases of acute diarrhoea in infancy was done. S. creatinine levels increased in 53 cases. ${ }^{[11]}$

\section{Case Fatality Rate:}

In the present study, out of 97 children 3 (3.1\%) children died and $94(96.9 \%)$ children survived.

All $3(3.1 \%)$ children who died of electrolyte abnormality also had high levels of blood urea and serum creatinine.

In a study by Shan GS showed, out of 46 patients with abnormal electrolyte pattern 5 died while there was no death amongst 11 patients with normal electrolytes. However, statistically significant mortality was observed in patients presenting with either hyponatremia or hypokalemia as compared to the group with normal electrolytes. ${ }^{[13]}$

\section{Conclusion}

The present study aimed at noting the biochemical changes in patients having acute diarrhoea. Like any other electrolyte abnormalities which occur in conditions other than diarhoea, are basically asymptomatic \& does not require aggressive correction of electrolytes. They do very well with ORS \& fluid correction as recommended by W.H.O.

References 
1. Acute Gastroenteritis in Children ; Nelson's Textbook of paediatrics: 1st South-Asia edition, Chapter 340, Pg No: 1854.

2. Govt of India (2014), National Health Profile 2013 (Jan-Dec), DGHS, Central Bureau of Health Intelligence, Ministry of Health and Family Welfare, New Delhi.

3. Begum JA, Hoque MM, Hussain M (2010) Impact of electrolyte disturbances in outcome of acute diarrhoea in children. DS (Child)Health J 26: 36-40.

4. M M Okposio et.al, Point-of-Admission Serum Electrolyte Profile of Children less than Five Years Old with Dehydration due to Acute Diarrhoea, Tropical Medicine and Health. 2015:43(4);247-252.

5. Conway SP, Phillips RR, Panday S. Admission to hospital with gastroenteritis. Archives of disease in childhood. 1990 Jun 1;65(6):57984.

6. Habibullah Barbar et. al Serum Electrolyte Disturbances in Acute Diarrhoea among Children Less Than 5 Years of Age, P J M H S. 2016:10(4);1231-1234.

7. Ahmad MS, Wahid A, Ahmad M, Mahboob N, Mehmood R. Prevalence of electrolyte disorders among cases of diarrhea with severe dehydration and correlation of electrolyte levels with age of the patients. Journal of the College of Physicians and Surgeons--Pakistan: JCPSP. 2016 May 1;26(5):394-8.

8. Srivastava AK, Bhatnagar JK, Prasad BG, Sharma NL. A clinical aetiological study of diarrhoea in hospitalized children at Lucknow. Indian Journal of Medical Research. 1973;61(4):596-602.

9. Behera SK, Mohapatra SS, Kar S, Das D, Panda C. Incidence and mortality of hospitalized diarrhoea cases. Part III. Indian pediatrics. 1980 Jul;17(7):607.

10. Gauchan E et.al Relationship of Renal Function Tests and Electrolyte Levels with Severity of Dehydration in Acute Diarrhea, J Nepal Health Res Counc. 2015;13(29).

11. Purohit KR, Jyotsna PS. Electrolyte disturbances in acute diarrhoea. The Indian Journal of Pediatrics. 1971;38(10):393-5.

12. Soleimani A, Foroozanfard F, Tamadon MR. Evaluation of water and electrolytes disorders in severe acute diarrhea patients treated by WHO protocol in eight large hospitals in Tehran; a nephrology viewpoint. Journal of renal injury prevention. 2017;6(2):109.

13. Shah GS, Das BK, Kumar S, Singh MK, Bhandari GP. Acid base and electrolyte disturbance in diarrhoea. Kathmandu University medical journal (KUMJ). 2007;5(1):60-2.

Copyright: (C) the author(s), 2019. It is an open-access article distributed under the terms of the Creative Commons Attribution License (CC BY 4.0), which permits authors to retain ownership of the copyright for their content, and allow anyone to download, reuse, reprint, modify, distribute and/or copy the content as long as the original authors and source are cited.

How to cite this article: Kumar SSV, Chakravarthi GK. Study on Renal Function in Acute Diarrheal Disease with Dehydration. Asian J. Clin. Pediatr. Neonatol.2019;7(3):24-27.

DOI: dx.doi.org/10.21276/ajcpn.2019.7.3.7

Source of Support: Nil, Conflict of Interest: None declared. 